\title{
ECOP Criterion for Irreversible Three-Heat-Source Absorption Refrigerators
}

\author{
Paiguy Armand Ngouateu Wouagfack and Réné Tchinda
}

Additional information is available at the end of the chapter

http://dx.doi.org/10.5772/51547

\section{Introduction}

In this chapter, the optimization analysis based on the new thermo-ecological criterion (ECOP) first performed by Ust et al. [1] for the heat engines is extended to an irreversible three-heat-source absorption refrigerator. The thermo-ecological objective function ECOP is optimized with respect to the temperatures of the working fluid. The maximum ECOP and the corresponding optimal temperatures of the working fluid, coefficient of performance, specific cooling load, specific entropy generation rate and heat-transfer surface areas in the exchangers are then derived analytically. Comparative analysis with the COP criterion is carried out to prove the utility of the ecological coefficient of performance criterion.

\section{Thermodynamics analysis}

The main components of an absorption refrigeration system are a generator, an absorber, a condenser and an evaporator as shown schematically in Fig. 1 [2]. In the shown model, $\dot{Q}_{H}$ is the rate of absorbed heat from the heat source at temperature $T_{H}$ to generator, $\dot{Q}_{C}$ and $Q_{A}$ are, respectively, the heat rejection rates from the condenser and absorber to the heat sinks at temperatures $T_{C}$ and $T_{A}$ and $\dot{Q}_{L}$ is the heat input rate from the cooling space at temperature $T_{L}$ to the evaporator. In absorption refrigeration systems, usually $\mathrm{NH}_{3} / \mathrm{H}_{2} \mathrm{O}$ and $\mathrm{LiBr} / \mathrm{H}_{2} \mathrm{O}$ are used as the working substances, and these substances abide by ozone depletion regulations, since they do not consist of chlorofluorocarbons. In Fig. 1, the liquid rich solution at state 1 is pressurized to state 1 ' with a pump. In the generator, the working fluid is concentrated to state 3 by evaporating the working medium by means of $Q_{H}$ heat rate input. The weak solution at state 2 passes through the expansion valve into the absorber with a pressure reduction $\left(2-2^{\prime}\right)$. In the condenser, the working fluid at 
state 3 is condensed to state 4 by removing $\dot{Q}_{C}$ heat rate. The condensed working fluid at state 4 is then throttled by a valve and enters the evaporator at state $4^{\prime}$. The liquid working fluid is evaporated due to heat transfer rate $\dot{Q}_{L}$ from the cooling space to the working fluid $\left(4^{\prime}-5\right)$. Finally, the vaporized working fluid is absorbed by the weak solution in the absorber, and by means of $Q_{A}$ heat rate release in the absorber, state 1 is reached.

Work input required by the solution pump in the system is negligible relative to the energy input to the generator and is often neglected for the purpose of analysis. Under such assumption, the equation for the first law of thermodynamics is written as:

$$
\dot{Q}_{H}+\dot{Q}_{L}-\dot{Q}_{C}-\dot{Q}_{A}=0
$$

Absorption refrigeration systems operate between three temperature levels, if $T_{A}=T_{C}$, or four temperature levels when $T_{A} \neq T_{C}$. In this chapter, by taking $T_{A}=T_{C}$, the cycle of the working fluid consists of three irreversible isothermal and three irreversible adiabatic processes. The temperatures of the working fluid in the three isothermal processes are different from those of the external heat reservoirs so that heat is transferred under a finite temperature difference, as shown in Fig. 2 where

$$
\dot{Q}_{O}=\dot{Q}_{C}+\dot{Q}_{A}
$$

$T_{1}$ and $T_{2}$ are, respectively, the temperatures of the working fluid in the generator and evaporator. It is assumed that the working fluid in the condenser and absorber has the same temperature $T_{3}$ [2]. $Q_{L C}$ is the heat leak from the heat sink to the cooled space.

The heat exchanges between the working fluid and heat reservoirs obey a linear heat transfer law, so that the heat-transfer equations in the generator, evaporator, condenser and absorber are, respectively, expressed as follows:

$$
\begin{gathered}
\dot{Q}_{H}=U_{H} A_{H}\left(T_{H}-T_{1}\right) \\
\dot{Q}_{L}=U_{L} A_{L}\left(T_{L}-T_{2}\right) \\
\dot{Q}_{O}=U_{O}\left(A_{A}+A_{C}\right)\left(T_{3}-T_{O}\right)
\end{gathered}
$$

where $A_{H}, A_{L}, A_{C}$ and $A_{A}$ are, respectively, the heat-transfer areas of the generator, evaporator, condenser and absorber, $U_{H}$ and $U_{L}$ are, respectively, the overall heat-transfer coefficients of the generator and evaporator, and it is assumed that the condenser and absorber have the same overall heat-transfer coefficient $U_{O}[2]$. 


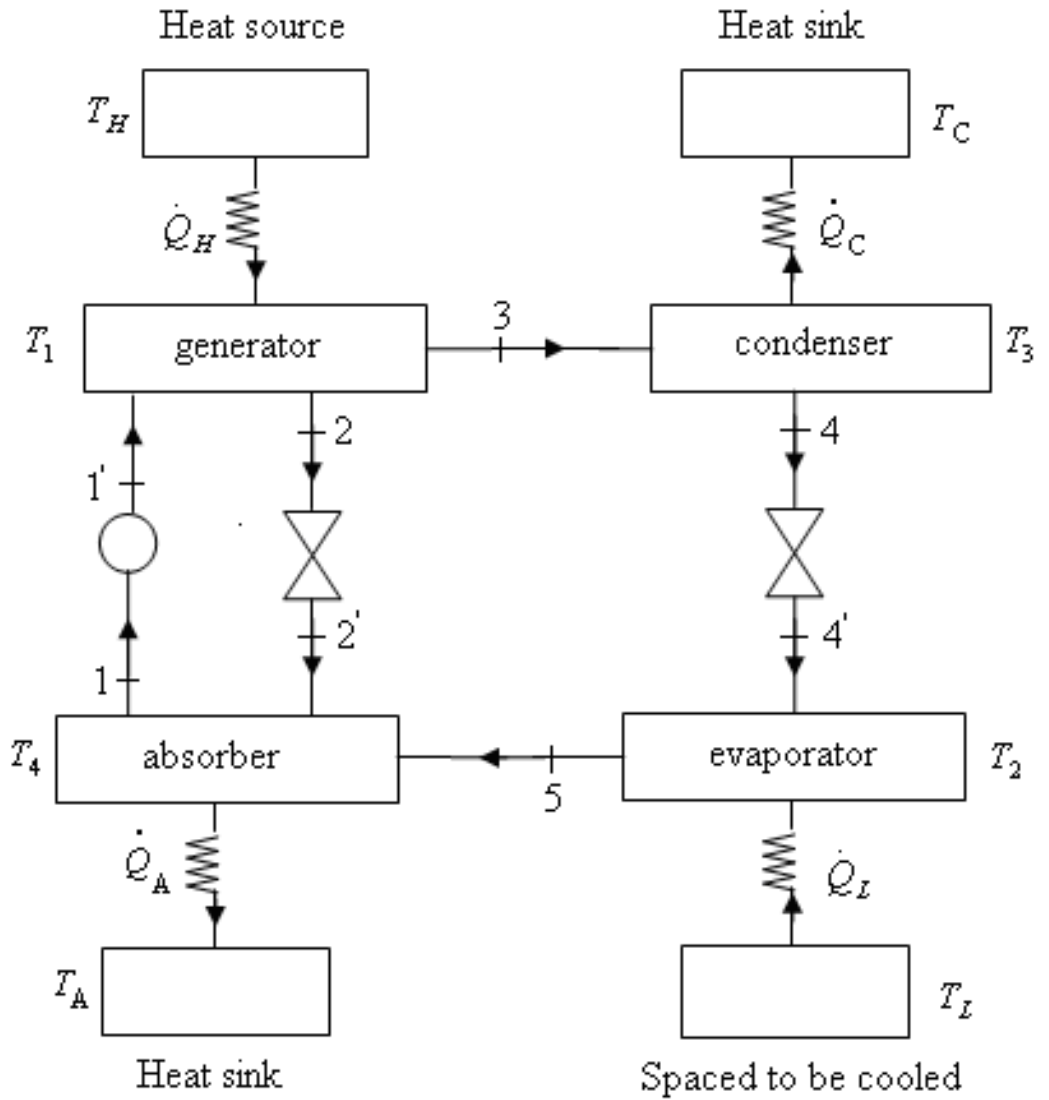

Figure 1. Schematic diagram of absorption refrigeration system [2]

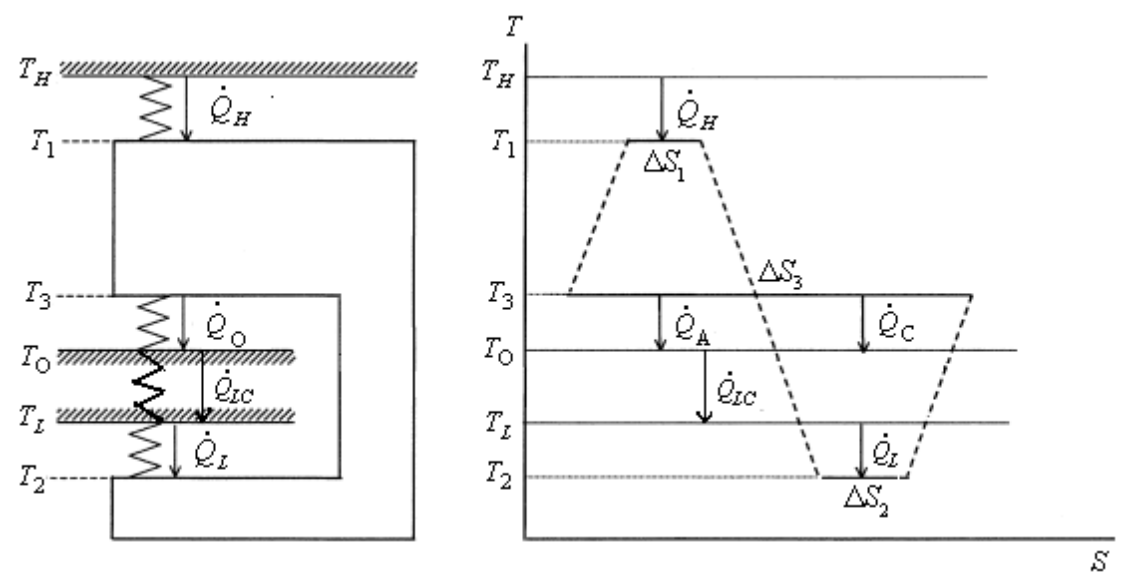

Figure 2. Considered irreversible absorption refrigeration model and its T-S diagram. 
The absorption refrigeration system does not exchange heat with other external reservoirs except for the three heat reservoirs at temperatures $T_{H}, T_{L}$ and $T_{O}$, so the total heat-transfer area between the cycle system and the external heat reservoirs is given by the relationships:

$$
A=A_{H}+A_{L}+A_{O}
$$

where

$$
A_{O}=A_{C}+A_{A}
$$

The rate of heat leakage $\dot{Q}_{L C}$ from the heat sink at temperature $T_{O}$ to the cold reservoir at temperature $T_{L}$ was first provided by Bejan [3] and it is given as:

$$
\dot{Q}_{L C}=K_{L C}\left(T_{O}-T_{L}\right)
$$

where $K_{L C}$ is the heat leak coefficient.

Real absorption refrigerators are complex devices and suffer from a series of irreversibilities. Besides the irreversibility of finite rate heat transfer which is considered in the endoreversible cycle models and the heat leak from the heat sink to the cooled space, there also exist other sources of irreversibility. The internal irreversibilities that result from friction, mass transfer and other working fluid dissipations are an another main source of irreversibility, which can decrease the coefficient of performance and the cooling load of absorption refrigerators. The total effect of the internal irreversibilities on the working fluid can be characterized in terms of entropy production. An irreversibility factor is introduced to describe these internal irreversibilities:

$$
I=\frac{\Delta S_{3}}{\Delta S_{1}+\Delta S_{2}}
$$

On the basis of the second law of thermodynamics, $\Delta S_{3}>\Delta S_{1}+\Delta S_{2}$ for an internally irreversible cycle, so that $I>1$. If the internal irreversibility is neglected, the cycle is endoreversible and so $I=1$. The second law of thermodynamics for an irreversible threeheat-source cycle requires that:

$$
\oint \frac{\delta \dot{Q}}{T}=\frac{\dot{Q}_{H}}{T_{1}}+\frac{\dot{Q}_{L}}{T_{2}}-\frac{\dot{Q}_{O}}{T_{3}} \leq 0
$$

From Eq. (9), the inequality in Eq. (10) is written as:

$$
\frac{\dot{Q}_{H}}{T_{1}}+\frac{\dot{Q}_{L}}{T_{2}}-\frac{\dot{Q}_{O}}{I T_{3}}=0
$$


The coefficient of performance of the irreversible three-heat-source absorption refrigerator is:

$$
\operatorname{COP}=\frac{\dot{Q}_{L}-\dot{Q}_{L C}}{\dot{Q}_{H}}=\frac{\dot{Q}_{L}}{\dot{Q}_{H}}\left(1-\frac{\dot{Q}_{L C}}{\dot{Q}_{L}}\right)
$$

From Eq. (6), it is expressed as:

$$
A_{L}=\frac{A}{1+\frac{A_{H}}{A_{L}}+\frac{A_{O}}{A_{L}}}
$$

Using Eqs. (3)-(5), Eq. (13) is rewritten as:

$$
A_{L}=\frac{A}{1+\frac{\dot{Q}_{H}}{\dot{Q}_{L}} \frac{U_{L}\left(T_{L}-T_{2}\right)}{U_{H}\left(T_{H}-T_{1}\right)}+\frac{\dot{Q}_{O}}{\dot{Q}_{L}} \frac{U_{L}\left(T_{L}-T_{2}\right)}{U_{O}\left(T_{3}-T_{O}\right)}}
$$

Combining Eqs. (1) and (11), the following ratios are derived:

$$
\begin{aligned}
& \frac{\dot{Q}_{L}}{\dot{Q}_{H}}=\frac{T_{2}\left(T_{1}-I T_{3}\right)}{T_{1}\left(I T_{3}-T_{2}\right)} \\
& \frac{\dot{Q}_{O}}{\dot{Q}_{L}}=\frac{I T_{3}\left(T_{1}-T_{2}\right)}{\left(T_{1}-I T_{3}\right) T_{2}}
\end{aligned}
$$

The first is the coefficient of performance of the irreversible three-heat-source absorption refrigeration cycle without heat leak losses.

Substituting Eqs. (15) and (16) into Eq. (14), the heat-transfer area of the evaporator is expressed as a function of $T_{1}, T_{2}$ and $T_{3}$ for a given total heat-transfer areas:

$$
A_{L}=\frac{A}{1+\frac{U_{L} T_{1}\left(I T_{3}-T_{2}\right)\left(T_{L}-T_{2}\right)}{U_{H}\left(T_{H}-T_{1}\right)\left(T_{1}-I T_{3}\right) T_{2}}+\frac{U_{L} I T_{3}\left(T_{1}-T_{2}\right)\left(T_{L}-T_{2}\right)}{U_{O}\left(T_{3}-T_{O}\right)\left(T_{1}-I T_{3}\right) T_{2}}}
$$

By investigating similar reasoning, the heat-transfer areas of the generator and of condenser and absorber are given respectively by:

$$
A_{H}=\frac{A}{1+\frac{U_{H} T_{2}\left(T_{1}-I T_{3}\right)\left(T_{H}-T_{1}\right)}{U_{L} T_{1}\left(I T_{3}-T_{2}\right)\left(T_{L}-T_{2}\right)}+\frac{U_{H} I T_{3}\left(T_{1}-T_{2}\right)\left(T_{H}-T_{1}\right)}{U_{O} T_{1}\left(I T_{3}-T_{2}\right)\left(T_{3}-T_{O}\right)}}
$$


and

$$
A_{O}=\frac{A}{1+\frac{U_{O} T_{1}\left(I T_{3}-T_{2}\right)\left(T_{3}-T_{O}\right)}{U_{H} I T_{3}\left(T_{1}-T_{2}\right)\left(T_{H}-T_{1}\right)}+\frac{U_{O} T_{2}\left(T_{1}-I T_{3}\right)\left(T_{3}-T_{O}\right)}{U_{L} I T_{3}\left(T_{1}-T_{2}\right)\left(T_{L}-T_{2}\right)}}
$$

Substituting Eq. (17) into Eq. (4):

$$
\dot{Q}_{L}=\frac{A}{\frac{1}{U_{L}\left(T_{L}-T_{2}\right)}+\frac{T_{1}\left(I T_{3}-T_{2}\right)}{U_{H}\left(T_{H}-T_{1}\right)\left(T_{1}-I T_{3}\right) T_{2}}+\frac{I T_{3}\left(T_{1}-T_{2}\right)}{U_{O}\left(T_{3}-T_{O}\right)\left(T_{1}-I T_{3}\right) T_{2}}}
$$

Combining Eqs. (8), (12), (15) and (20), the coefficient of performance of the irreversible three-heat-source refrigerator as a function of the temperatures $T_{1}, T_{2}$ and $T_{3}$ of the working fluid in the generator, evaporator, condenser and absorber is obtained:

$$
C O P=\frac{T_{2}\left(T_{1}-I T_{3}\right)}{T_{1}\left(I T_{3}-T_{2}\right)}\left\{1-\xi\left(T_{O}-T_{L}\right)\left[\frac{1}{U_{L}\left(T_{L}-T_{2}\right)}+\frac{T_{1}\left(I T_{3}-T_{2}\right)}{U_{H}\left(T_{H}-T_{1}\right)\left(T_{1}-I T_{3}\right) T_{2}}+\frac{I T_{3}\left(T_{1}-T_{2}\right)}{U_{O}\left(T_{3}-T_{O}\right)\left(T_{1}-I T_{3}\right) T_{2}}\right]\right\}
$$

where the parameter

$$
\xi=\frac{K_{L C}}{A}
$$

represents the heat leakage coefficient and its dimension is $\mathrm{w} /\left(\mathrm{Km}^{2}\right)$

The specific cooling load of the irreversible three-heat-source refrigerator is deduced as:

$$
r=\frac{\dot{Q}_{L}-\dot{Q}_{L C}}{A}=\left[\frac{1}{U_{L}\left(T_{L}-T_{2}\right)}+\frac{T_{1}\left(I T_{3}-T_{2}\right)}{U_{H}\left(T_{H}-T_{1}\right)\left(T_{1}-I T_{3}\right) T_{2}}+\frac{I T_{3}\left(T_{1}-T_{2}\right)}{U_{O}\left(T_{3}-T_{O}\right)\left(T_{1}-I T_{3}\right) T_{2}}\right]^{-1}-\xi\left(T_{O}-T_{L}\right)
$$

The specific entropy production rate of the irreversible three-heat-source absorption refrigerator is:

$$
s=\frac{\dot{\sigma}}{A}=\frac{\frac{\dot{Q}_{O}-\dot{Q}_{L C}}{T_{O}}-\frac{\dot{Q}_{H}}{T_{H}}-\frac{\dot{Q}_{L}-\dot{Q}_{L C}}{T_{L}}}{A}
$$

Using Eq. (1) $s$ is rewritten as: 


$$
s=\left(\frac{1}{T_{L}}-\frac{1}{T_{O}}\right) \frac{\dot{Q}_{L C}}{A}+\left(\frac{1}{T_{O}}-\frac{1}{T_{H}}\right) \frac{\dot{Q}_{H}}{\dot{Q}_{L}} \frac{\dot{Q}_{L}}{A}+\left(\frac{1}{T_{O}}-\frac{1}{T_{L}}\right) \frac{\dot{Q}_{L}}{A}
$$

or

$$
s=\left(\frac{1}{T_{O}}-\frac{1}{T_{H}}\right) \frac{\dot{Q}_{H}}{A}+\left(\frac{1}{T_{O}}-\frac{1}{T_{L}}\right) \frac{\dot{Q}_{L}-\dot{Q}_{L C}}{A}
$$

Substituting Eqs.(8), (15) and (20) into Eq. (25), the specific entropy production rate as a function of $T_{1}, T_{2}$ and $T_{3}$ is given by:

$$
s=\left(\frac{1}{T_{L}}-\frac{1}{T_{O}}\right)\left\{\xi\left(T_{O}-T_{L}\right)-\left[1-\frac{\varepsilon_{r} T_{1}\left(I T_{3}-T_{2}\right)}{T_{2}\left(T_{1}-I T_{3}\right)}\right]\left[\frac{1}{U_{L}\left(T_{L}-T_{2}\right)}+\frac{T_{1}\left(I T_{3}-T_{2}\right)}{U_{H}\left(T_{H}-T_{1}\right)\left(T_{1}-I T_{3}\right) T_{2}}+\frac{I T_{3}\left(T_{1}-T_{2}\right)}{U_{O}\left(T_{3}-T_{O}\right)\left(T_{1}-I T_{3}\right) T_{2}}\right]^{-1}\right\}
$$

where

$$
\varepsilon_{r}=\frac{\left(1-\frac{T_{O}}{T_{H}}\right)}{\left(\frac{T_{O}}{T_{L}}-1\right)}
$$

is the coefficient of performance for reversible three-heat-source refrigerator.

According to the definition of the general thermo-ecological criterion function for different heat engine models [4-9], a two-heat-source refrigerator [10, 11] and three-heat-source absorption refrigerator [2], the new thermo-ecological objective function called ecological coefficient of performance $(E C O P)$ of an absorption refrigerator is defined as:

$$
E C O P=\frac{\dot{Q}_{L}-\dot{Q}_{L C}}{T_{\text {env }} \dot{\sigma}}=\frac{\dot{Q}_{L}-\dot{Q}_{L C}}{A T_{\text {env }} S}
$$

Putting Eq.(26) into Eq. (29):

$$
E C O P=\frac{1}{T_{e n v}\left[\frac{1}{T_{O}}-\frac{1}{T_{H}}+\left(\frac{1}{T_{O}}-\frac{1}{T_{L}}\right) \frac{1}{C O P}\right]}
$$

When Eq. (21) is put in Eq. (30), the ecological coefficient of performance of the irreversible three-heat-source absorption refrigerator as a function of $T_{1}, T_{2}$ and $T_{3}$ is derived as: 


$$
E C O P=\frac{\frac{1}{T_{\text {env }}\left(T_{O}^{-1}-T_{L}^{-1}\right)}}{1-\frac{\varepsilon_{r} T_{1}\left(I T_{3}-T_{2}\right)}{T_{2}\left(T_{1}-I T_{3}\right)}\left\{1-\xi\left(T_{O}-T_{L}\right)\left[\frac{1}{U_{L}\left(T_{L}-T_{2}\right)}+\frac{T_{1}\left(I T_{3}-T_{2}\right)}{U_{H}\left(T_{H}-T_{1}\right)\left(T_{1}-I T_{3}\right) T_{2}}+\frac{I T_{3}\left(T_{1}-T_{2}\right)}{U_{O}\left(T_{3}-T_{O}\right)\left(T_{1}-I T_{3}\right) T_{2}}\right]\right\}^{-1}}
$$

where $T_{\text {env }}$ is the temperature in the environment conditions.

\section{Performance optimization for a three-heat-source irreversible absorption refrigerator based on ECOP criterion}

The ECOP function given in Eq. (31) is plotted with respect to the working fluid temperatures $\left(T_{1}, T_{2}\right.$ and $\left.T_{3}\right)$ for different internal irreversibility parameters as shown in Fig. 3(a), (b) and (c). As it can be seen from the figure, there exists a specific $T_{1}, T_{2}$ and $T_{3}$ that maximize the ECOP function for given $I$ and $\xi$ values. Therefore, Eq. (31) can be maximized (or optimized) with respect to $T_{1}, T_{2}$ and $T_{3}$. The optimization is carried out analytically.
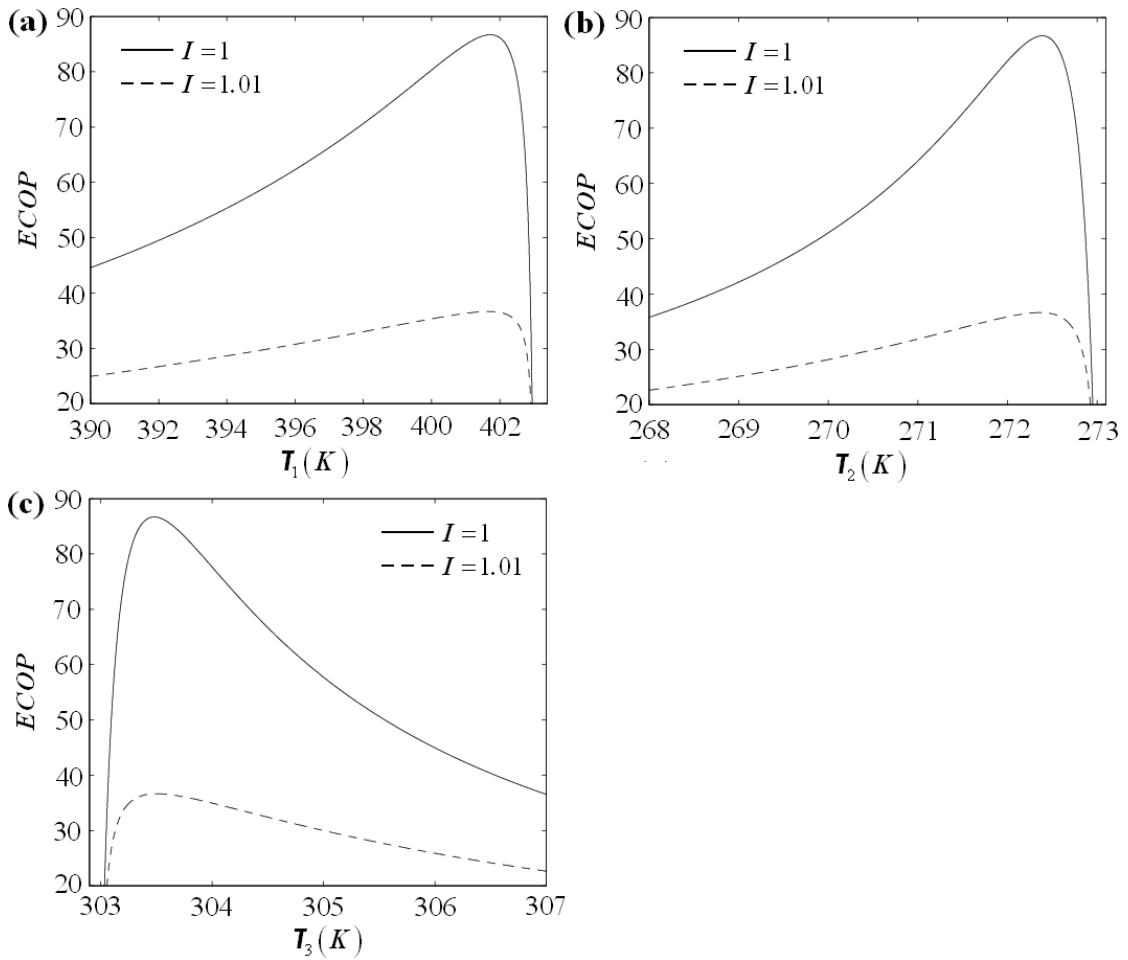

Figure 3. Variation of the ECOP objective function with respect to $T_{1}$ (a), $T_{2}$ (b) and $T_{3}$ (c) for different $I$ values $\left(T_{G}=403 \mathrm{~K}, T_{L}=273 \mathrm{~K}, T_{O}=303 \mathrm{~K}, T_{\text {env }}=290 \mathrm{~K}, U_{G}=1163 \mathrm{~W} / \mathrm{m}^{2} \mathrm{~K}\right.$, $U_{E}=2326 \mathrm{~W} / \mathrm{m}^{2} \mathrm{~K}, U_{O}=4650 \mathrm{~W} / \mathrm{m}^{2} \mathrm{~K}, K_{L}=1082 \mathrm{~W} / \mathrm{K}, A=1100 \mathrm{~m}^{2}$ ) 
For the sake of convenience, let

$$
\begin{gathered}
x=\frac{I T_{3}}{T_{1}} \\
y=\frac{I T_{3}}{T_{2}} \\
z=I T_{3}
\end{gathered}
$$

Then Eq. (31) is rewritten as:

$$
\text { ECOP }=\frac{\frac{1}{T_{\text {env }}\left(T_{O}^{-1}-T_{L}^{-1}\right)}}{1-\frac{\varepsilon_{r}(y-1)}{1-x}\left\{1-\xi\left(T_{O}-T_{E}\right)\left[\frac{y}{U_{L}\left(T_{L} y-z\right)}+\frac{x(y-1)}{U_{H}\left(T_{H} x-z\right)(1-x)}+\frac{y-x}{U(z-T)(1-x)}\right]\right]^{-1}}
$$

where

$$
T=I T_{O}
$$

and

$$
U=\frac{U_{O}}{I}
$$

Starting from Eq. (35), the extremal conditions:

$$
\begin{aligned}
& \frac{\partial E C O P}{\partial x}=0 \\
& \frac{\partial E C O P}{\partial y}=0 \\
& \frac{\partial E C O P}{\partial z}=0
\end{aligned}
$$

give respectively:

$$
\frac{1}{\xi\left(T_{O}-T_{E}\right)}-\frac{y}{U_{L}\left(T_{L} y-z\right)}-\frac{1}{U(z-T)}-\frac{z(y-1)}{U_{H}\left(T_{H} x-z\right)^{2}}=0
$$




$$
\begin{gathered}
\frac{1}{\xi\left(T_{O}-T_{E}\right)}-\frac{y}{U_{L}\left(T_{L} y-z\right)}-\frac{1}{U(z-T)}-\frac{z(y-1)}{U_{L}\left(T_{L} y-z\right)^{2}}=0 \\
\frac{y(1-x)}{U_{L}\left(T_{L} y-z\right)^{2}}+\frac{x(y-1)}{U_{H}\left(T_{H} x-z\right)^{2}}-\frac{y-x}{U(z-T)^{2}}=0
\end{gathered}
$$

Combining Eqs (41)-(43), the following general relation is found:

$$
\sqrt{U_{H}}\left(T_{H} x-z\right)=\sqrt{U_{L}}\left(T_{L} y-z\right)=\sqrt{U}(z-T)
$$

From Eqs (44), it is derived as:

$$
\begin{aligned}
& x=\frac{\left(1+b_{1}\right) z}{T_{H}}-\frac{b_{1} T}{T_{H}} \\
& y=\frac{\left(1+b_{2}\right) z}{T_{L}}-\frac{b_{2} T}{T_{L}}
\end{aligned}
$$

where

$$
\begin{aligned}
& b_{1}=\sqrt{\frac{U}{U_{H}}} \\
& b_{2}=\sqrt{\frac{U}{U_{L}}}
\end{aligned}
$$

When Eqs. (45) and (46) are substituted into Eq. (43):

$$
z=T \frac{D+b_{2}}{1+b_{2}}
$$

where

$$
D=\frac{1+\sqrt{d_{1}\left[1-\frac{T_{L}\left(1-d_{1}\right)}{T}\right]}}{1-d_{1}}
$$




$$
d_{1}=\xi \frac{\left(1+b_{2}\right)^{2}}{U}\left(\frac{T_{O}}{T_{L}}-1\right)
$$

Therefore Eqs. (45) and (46) are rewritten as:

$$
\begin{gathered}
x=\frac{T}{T_{H}} B_{1}(D+B) \\
y=\frac{T}{T_{L}} D
\end{gathered}
$$

where

$$
\begin{aligned}
& B=\frac{b_{2}-b_{1}}{1+b_{1}} \\
& B_{1}=\frac{1+b_{1}}{1+b_{2}}
\end{aligned}
$$

Using Eqs. (49), (52) and (53) with Eqs.(32)-(34), the corresponding optimal temperatures of the working fluid in the three isothermal processes when the ecological coefficient of performance is a maximum, are, respectively, determined by:

$$
\begin{gathered}
T_{1}^{*}=T_{H} \frac{D+b_{2}}{\left(1+b_{1}\right)(D+B)} \\
T_{2}^{*}=T_{L} \frac{D+b_{2}}{D\left(1+b_{2}\right)} \\
T_{3}^{*}=T_{O} \frac{D+b_{2}}{1+b_{2}}
\end{gathered}
$$

Substituting Eqs. (56)-(58) into Eqs. (21), (23), (27) and (31) the maximum ECOP function and the corresponding optimal coefficient of performance, optimal specific cooling load and optimal specific entropy generation rate are derived, respectively, as:

$$
E C O P_{\max }=\frac{1}{T_{\text {env }}\left(T_{O}^{-1}-T_{L}^{-1}\right)}
$$




$$
\begin{aligned}
& 1 \\
& 1-\frac{\varepsilon_{r} T_{H}\left(T D-T_{L}\right)}{\left[T_{H}-B_{1}(D+B) T\right] T_{L}}\left\{1-\xi\left(T_{O}-T_{L}\right) \frac{T_{H} D-B_{1}{ }^{2}(D+B)\left(T_{L}+B D T\right)}{U^{*} B_{1}^{2}(D-1)\left[T_{H}-B_{1}(D+B) T\right] T_{L}}\right\}^{-1} \\
& \operatorname{COP}^{*}=\frac{\left[T_{H}-B_{1}(D+B) T\right] T_{L}}{T_{H}\left(T D-T_{L}\right)}\left\{1-\xi\left(T_{O}-T_{L}\right) \frac{T_{H} D-B_{1}^{2}(D+B)\left(T_{L}+B D T\right)}{U^{*} B_{1}^{2}(D-1)\left[T_{H}-B_{1}(D+B) T\right] T_{L}}\right\} \\
& r^{*}=\frac{U^{*} B_{1}^{2}(D-1)\left[T_{H}-B_{1}(D+B) T\right] T_{H}}{T_{H} D-B_{1}^{2}(D+B)\left(T_{L}+B D T\right)}-\xi\left(T_{O}-T_{L}\right) \\
& s^{*}=\left(\frac{1}{T_{L}}-\frac{1}{T_{O}}\right)\left\{\xi\left(T_{O}-T_{L}\right)-\left[1-\frac{\varepsilon_{r} T_{H}\left(T D-T_{L}\right)}{\left[T_{H}-B_{1}(D+B) T\right] T_{L}}\right]\left[\frac{U^{*} B_{1}^{2}(D-1)\left[T_{H}-B_{1}(D+B) T\right] T_{L}}{T_{H} D-B_{1}^{2}(D+B)\left(T_{L}+B D T\right)}\right]\right\}
\end{aligned}
$$

where

$$
U^{*}=\frac{U}{\left(1+b_{1}\right)^{2}}
$$

From Eqs. (17)-(19) and (56)-(58), it is found that, when the three-heat-source absorption refrigerator is operated in the state of maximum ecological coefficient of performance, the relations between the heat-transfer areas of the heat exchangers and the total heat-transfer area are determined by:

$$
\begin{gathered}
A_{H}{ }^{*}=A \frac{b_{1}}{1+b_{1}} \frac{B_{1}{ }^{2}(D+B)\left(T D-T_{L}\right)}{T_{H} D-B_{1}{ }^{2}(D+B)\left(T_{L}+B D T\right)} \\
A_{L}^{*}=A \frac{b_{2}}{1+b_{1}} \frac{D B_{1}\left[T_{H}-B_{1} T(D+B)\right]}{T_{H} D-B_{1}{ }^{2}(D+B)\left(T_{L}+B D T\right)} \\
A_{O}{ }^{*}=A \frac{1}{1+b_{1}} \frac{B_{1}\left[T_{H} D-B_{1} T_{L}(D+B)\right]}{T_{H} D-B_{1}{ }^{2}(D+B)\left(T_{L}+B D T\right)}
\end{gathered}
$$

From Equations (64)-(66), a concise optimum relation for the distribution of the heat-transfer areas is obtained as:

$$
\sqrt{U_{H}} A_{H}^{*}+\sqrt{U_{L}} A_{L}^{*}=\sqrt{U} A_{O}^{*}
$$


Obviously, this relation is independent of the heat leak and the temperatures of the external heat reservoirs.

\section{Comparison with COP criterion}

In Fig.4, the variation of the normalized ECOP $\left(\overline{E C O P}=\frac{E C O P}{E C O P_{\max }}\right)$, normalized COP ( $\left.\overline{C O P}=\frac{C O P}{C O P_{\max }}\right)$ and the specific cooling load (r) with respect to the specific entropy generation rate (s) are demonstrated. One interesting observation from this figure is that maximum of the ECOP and COP coincides although their functional forms are different: the coefficient of performance gives information about the necessary heat rate input in order to produce certain amount of cooling load and the ecological coefficient of performance gives information about the entropy generation rate or loss rate of availability in order to produce certain amount of cooling load. The maximum ECOP and COP conditions give the same amount of cooling load and entropy generation rate. It is also seen analytically that the performance parameters $T_{1}^{*}, T_{2}^{*}, T_{3}^{*}, A_{1}^{*}, A_{2}^{*}, A_{3}^{*}, r^{*}$, $s^{*}$ and $C O P^{*}=C O P_{\max }$ at the maximum ECOP and maximum COP are same. Getting the same performance at maximum ECOP and COP conditions is an expected and logical result. Since, for a certain cooling load the maximum COP results from minimum heat consumption so that minimum environmental pollution. The minimum environmental pollution is also achieved by maximizing the ECOP. Although the optimal performance conditions ECOP and COP criteria are same, their impact on the system design performance is different. The coefficient of performance is used to evaluate the performance and the efficiency of systems. This method only takes into account the first law of thermodynamics which is concerned only with the conversion of energy, and therefore, can not show how or where irreversibilities in a system or process occur. Also, when different sources and forms of energy are involved within a system, the COP criterion of a system doesn't describe its performance from the view point of the energy quality involved. This factor is taken into account by the second law of thermodynamics characterized by the entropy production which appears in the ecological coefficient of performance criterion (ECOP). This aspect is of major importance today since that with the requirement of a rigorous management of our energy resources, one should have brought to be interested more and more in the second principle of thermodynamics, because degradations of energy, in other words the entropy productions, are equivalent to consumption of energy resources. For this important reason, the ECOP criterion can enhance the system performance of the absorption refrigerators by reducing the irreversible losses in the system. A better understanding of the second law of thermodynamics reveals that the ecological coefficient of performance optimization is an important technique in achieving better operating conditions. 


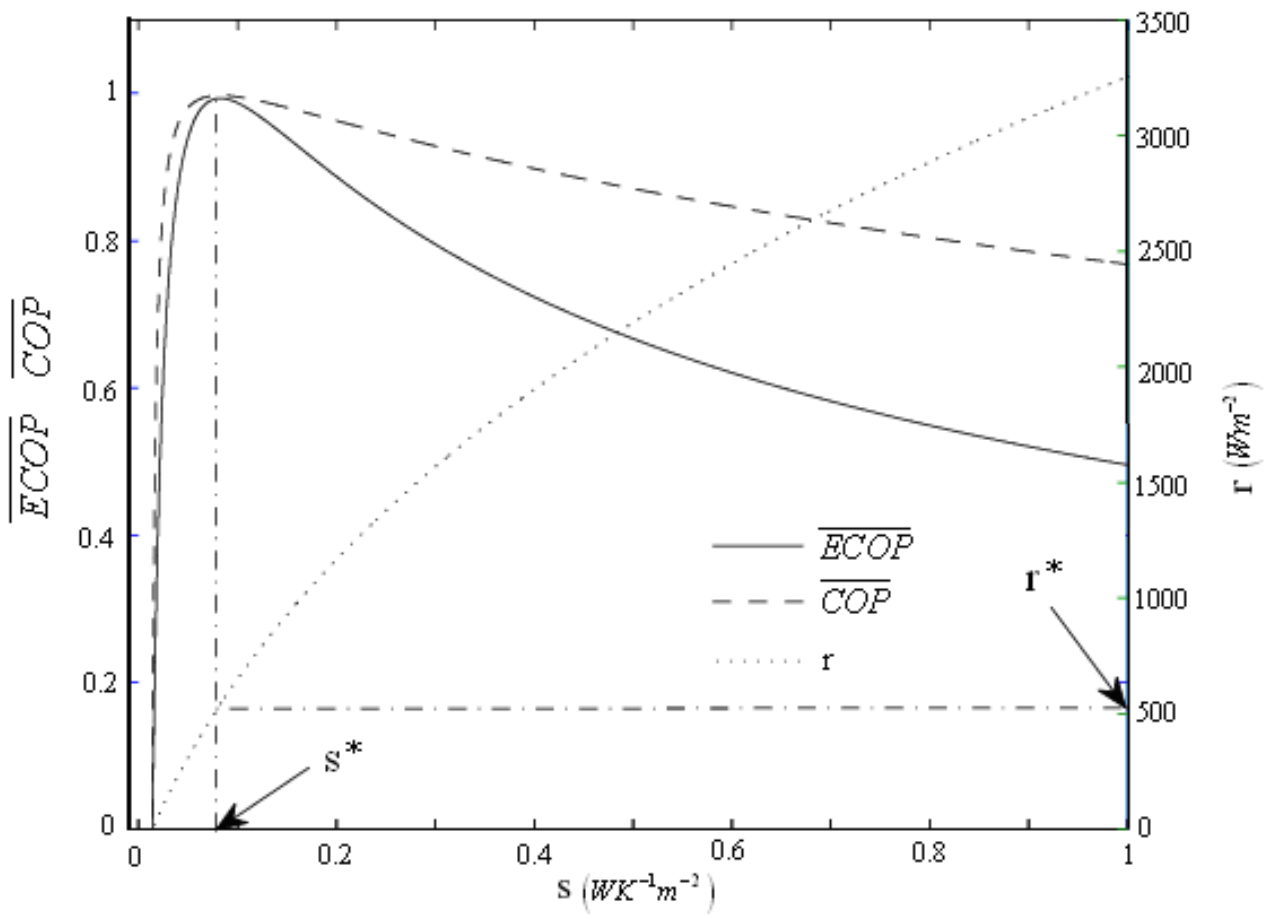

Figure 4. Variation of the normalized ECOP, normalized $C O P$ and the specific cooling load with respect to the specific entropy generation rate $\left(T_{G}=403 \mathrm{~K}, T_{L}=273 \mathrm{~K}, T_{O}=303 \mathrm{~K}, T_{\text {env }}=290 \mathrm{~K}\right.$, $U_{G}=1163 \mathrm{~W} / \mathrm{m}^{2} \mathrm{~K}, U_{E}=2326 \mathrm{~W} / \mathrm{m}^{2} \mathrm{~K}, U_{O}=4650 \mathrm{~W} / \mathrm{m}^{2} \mathrm{~K}, K_{L}=1082 \mathrm{~W} / \mathrm{K}, A=1100$ $m^{2}$ )

\section{Conclusion}

This chapter presented an analytical method developed to achieve the performance optimization of irreversible three-heat-source absorption refrigeration models having finiterate of heat transfer, heat leakage and internal irreversibility based on an objective function named ecological coefficient of performance (ECOP). The optimization procedure consists in defining the objective function ECOP in term of the temperatures of the working fluid in the generator, evaporator, condenser and absorber and using extremal conditions to determine analytically the maximum ECOP and the corresponding optimal design parameters. It also established comparative analyses with the COP criterion and shown that the performance parameters at the maximum ECOP and maximum COP are same. The three-heat-source absorption refrigerator cycles are the simplified models of the absorption refrigerators, but the four-heat-source absorption refrigerators cycles are closer to the real absorption refrigerators. 


\section{Author details}

Paiguy Armand Ngouateu Wouagfack

L2MSP, Department of Physics, University of Dschang, Dschang , Cameroon

Réné Tchinda

LISIE, University Institute of Technology Fotso Victor, University of Dschang, Bandjoun, Cameroon

\section{References}

[1] Ust, Y.: Ecological performance analysis and optimization of powergeneration systems, Ph.D. Thesis Progress Report, Yildiz Technical University, Istanbul. (2004).

[2] Ngouateu, Wouagfack, P. A., Tchinda, R.: Performance optimization of three-heatsource irreversible refrigerator based on a new thermo-ecological criterion. International Journal of Refrigeration. 34, 1008-1015 (2011).

[3] Bejan, A.: Theory of heat transfer-irreversible refrigeration plant. International Journal of Heat Transfer. 32, 1631-1639 (1989).

[4] Ust, Y., Sahin, B., Sogut, O. S.: Performance analysis and optimization of an irreversible Dual cycle based on ecological coefficient of performance (ECOP) criterion. Applied Energy. 82 (1), 23-39 (2005).

[5] Ust, Y., Sahin, Kodal, A.: Ecological coefficient of performance (ECOP) optimization for generalized irreversible Carnot heat engines. Journal of the Energy Institute. 78 (3), 145151 (2005).

[6] Ust, Y., Sahin,B., Kodal, A.: Performance analysis of an irreversible Brayton heat engine based on ecological coefficient of performance criterion. International Journal of Thermal Science. 45 (1), 94-101 (2006).

[7] Ust, Y., Sogut, O. S., Sahin, B., Durmayaz, A.: Ecological coefficient of performance (ECOP) optimization for an irreversible Brayton heat engine with variable-temperature thermal reservoirs. Journal of the Energy Institute. 79 (1), 47-52 (2006).

[8] Ust, Y., Sahin, B., Kodal, A., Akcay, I. H.: Ecological coefficient of performance analysis and optimization of an irreversible regenerative Brayton heat engine. Applied Energy. 83 (6), 558-572 (2006).

[9] Sogut, O. S., Ust, Y., Sahin, B.: The effects of intercooling and regeneration on the thermo-ecological performance analysis of an irreversible-closed Brayton heat engine with variable-temperature thermal reservoirs. Journal of Physics D: Applied Physics. 39, 4713-4721 (2006).

[10] Ust, Y., Sahin, B.: Performance optimization of irreversible refrigerators based on a new thermo-ecological criterion. International Journal of Refrigeration. 30, 527-534 (2007). 
[11] Ust, Y.: Performance analysis and optimization of irreversible air refrigeration cycles based on ecological coefficient of performance criterion. Applied Thermal Engineering. 29, 47-55 (2009). 